\title{
Investigation of fibre orientation using SEM micrograph and prediction of mechanical properties through micromechanical modelling
}

\author{
SUCHHANDA SRABANEE SWAIN, SUSHANTA K SAMAL, SMITA MOHANTY* and \\ SANJAY K NAYAK \\ Laboratory for Advanced Research in Polymeric Materials (LARPM), Central Institute of Plastics \\ Engineering \& Technology, Bhubaneswar 751024, India
}

MS received 19 August 2015; accepted 4 January 2016

\begin{abstract}
The present study concerns the fabrication of short sisal fibre-reinforced polypropylene (PP/SF) composites by melt mixing with different fibre length $(3,6$ and $10 \mathrm{~mm})$ comprising of $70 \%$ of matrix PP and $30 \%$ of SFs followed by injection moulding. The PP/MA-g-PP/SF composites were prepared with the ratio of 65:5:30 with the optimized fibre length of $6 \mathrm{~mm}$ at different mould temperatures $\left(25,45\right.$ and $\left.65^{\circ} \mathrm{C}\right)$ in a similar fashion. This work also further extended to study the effect of fibre orientation of the composites by numerical calculation of secondorder orientation tensor. To evaluate the fibre orientations PP/MA-g-PP/SF composites at different mould temperatures, scanning electron microscope micrographs were used to estimate the accurate principal directions and two-dimensional fibre orientation distributions through centre coordinates of the elliptical fibre images. Finally, a mathematical model of modified rule of mixture was adopted to compare the predicted tensile strength and modulus with the experimental findings.
\end{abstract}

Keywords. Polypropylene; sisal fibre; fibre orientation distribution; orientation tensor; micromechanical modelling.

\section{Introduction}

Preservation of environmental and economic balance due to natural fibre-reinforced polymer composites consider for high performance end user applications in automobiles, aerospace, defence, marine, building, furniture and packaging. The qualitative performance of the fibre-reinforced composites primarily depends upon the interface which allows transferring the stress from the matrix to the fibre efficiently. The properties of the composites are mostly ruled by fibre type, environmental conditions, processing methods fibre surface modification and microstructural parameters such as fibre aspect ratio, length, orientation, size distribution, etc. $[1,2]$. The distribution of fibre orientation in injection moulded parts is quite dissimilar in nature, i.e. some region has random orientation, while others preferentially align in certain direction. The reinforced composites are stronger, stiffer in the fibre orientation direction and weaker and more complaint in the direction of least orientation. Maximal anisotropy is achieved when all the fibres are aligned unidirectionally [3].

For injection moulded short fibre-reinforced composite, the global properties are usually heterogeneous and are mainly dependent on fibre orientation distribution and become the crucial factor for the determination of numerous physical, mechanical, thermal and rheological properties of composites.

\footnotetext{
*Author for correspondence (papers.journal@gmail.com)
}

The anisotropy in a moulded composite is a direct consequence of the fibre orientation that evolves during mould filling. A complex flow field is generated, and the fibre orientation strongly depends upon the processing conditions. There are various factors affecting the quality of injection moulded products which includes flow rate, injection pressure, injection speed, injection time, filling time, cooling time, ejecting pressure, melt temperature, mould temperature, mould geometry shape, material property of melt and heat transfer action of flow field [4,5].

The present study emphasizes mainly on two topics (a) processing and morphological properties of short fibre reinforced injection moulded thermoplastics, (b) modelling and measurement of fibre orientation distribution followed by the prediction of mechanical properties of the composites by using micromechanical model [6]. These modellings have more importance and can shed light on the relationship between composite microstructure (fibre orientation) and the properties of the composite.

Accurate description of microstructure in terms of fibre volume and fibre orientation can be possible by the analysis of 2-D or 3-D images of material. 3-D images with a sufficient resolution obtained from microtomography is very useful for studying the small diameter fibres of about 5-15 $\mu \mathrm{m}$, but this technique scarcely used and very expensive for largescale studies [7]. To measure an accurate estimation of the fibre orientation, confocal microscopy is another technique used to obtain 3-D images of the material which performs multiple optical sections of the sample to construct 3-D data 
$[8,9]$. An alternative method which does not require 3-D imaging, but relies on the observation of thin parallel slices and yields worthwhile results. However, it is laborious to obtain perfectly parallel slices of an acceptable thickness [10-12].

Fibre orientation measurement techniques by using images obtained by light reflection microscopy, optical microscopy, contact microradiography, ultrasonic velocity measuring, scanning electron microscopy and acoustic scanning microscopy have been reported by many authors [1315]. In this image analysis technique, the sections of the fibres are as circle, ellipse or rectangle based on the direction of fibre dispersion in the matrix. Fibre orientation can be possible to calculate using in-sectioning-plane angle $(\varphi)$ and out-of-sectioning-plane angle $(\theta)$ from the geometry and alignment of those entities [16].

Three-dimensional orientation distributions in terms of 4th-order tensors have been described by Advani and Tucker [17] and relate the values for the prediction of properties of the fibre suspensions, thereby building a bridge between processing parameters and final performance properties. The second-order tensor is suggested as comprehensive descriptors of the fibre orientation state, which is described by many authors. The short fibre orientation (FO) state from the geometry of the fibre cross-section has been described Advani and Tucker III [18] by using the second-order orientation tensor. Second-order tensor is very effective in the description of the FO state and can be directly applied to predict both rheological and mechanical properties of the fibre-reinforced polymer composites $[19,20]$.

In the present investigation, the influence of different mould temperatures i.e. 25,45 and $65^{\circ} \mathrm{C}$ on mechanical properties of PP/MA-g-PP/SF composite has been studied. The main goal of the present research is the prediction of the anisotropy effect induced by the FOD on the mechanical properties of the PP/SF/MAPP composites. The use of orientation tensor in combination with image processing technique to aid the prediction of fibre orientation in the composites has been well described. MRoM micromechanical model has been used to predict tensile strength and modulus of the composites fabricated at different mould temperatures. The accuracy of the model is evaluated by comparing with the corresponding experimental findings to understand the relationship between the processing conditions, the fibre orientation distribution and the properties of the composite. These works also extend to study the effect of critical fibre length on the mechanical performance PP/MA-g-PP/SF composites.

\section{Materials and methods}

Isotactic polypropylene (PP) with density $0.9 \mathrm{~g} \mathrm{cc}^{-1}$ and MFI between 1 and $12 \mathrm{~g}$ per $10 \mathrm{~min}\left(230^{\circ} \mathrm{C}, 2.16 \mathrm{~kg}\right)$ obtained from M/s Cargill Dow (Bair, US-NE) was taken as matrix polymer. Sisal fibres (SFs, Agave sisalana), obtained from M/s Tripura Mushroom Growers Welfare Society Tripura, India, with a density of $1.5 \mathrm{~g} \mathrm{cc}^{-1}$ and diameter $0.168 \mathrm{~mm}$ was used as reinforcement. Improvement in bonding between the fibre
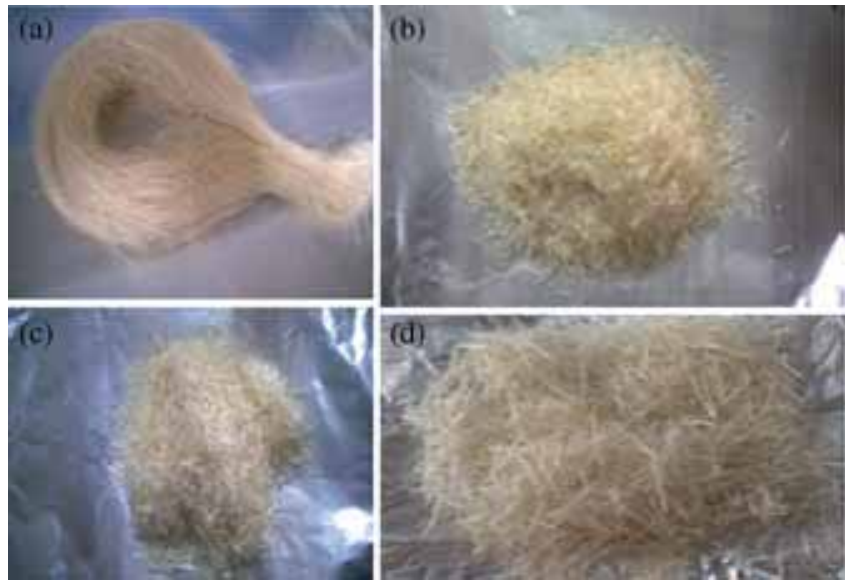

Figure 1. (a) Supplied SF, (b) 3, (c) 6 and (d) $10 \mathrm{~mm}$ lengths of SF.

and matrix was achieved by the use of functionalized components: a polypropylene grafted maleic anhydride (MA-g-PP) collected from Merck Specialties Pvt. Ltd, Mumbai, India.

\subsection{Preparation of chopped SF with different fibre length}

$\mathrm{SF}$ in the form of bundles were cut into a length of $13-15 \mathrm{~cm}$, and scoured in mild detergent solution at $60^{\circ} \mathrm{C}$ for about $2 \mathrm{~h}$ to remove water soluble contaminants like dust and other impurities from the fibre surface. Then the fibres were washed in distilled water and dried in air for 2 days to eliminate the absorbed moisture. And finally the fibres were chopped into desired lengths like 3, 6 and $10 \mathrm{~mm}$ required for the fabrication of the composites. Different lengths of SF were dried perfectly before processing to reduce the moisture content in the samples because it could lead to air bubbles formation in the specimens and hence poor mechanical properties were obtained. The appearances of the fibres of different fibre lengths used in this study are shown in figure 1a-d.

\subsection{Fabrication of composites}

Composites were fabricated by melt mixing with different fibre lengths (3, 6 and $10 \mathrm{~mm}$ ) comprising $70 \%$ of matrix PP and $30 \%$ of SFs in a batch mixer of $69 \mathrm{~cm}^{3}$ volumetric capacity (M/s Haake, Germany) followed by injection moulding (Microcompounder with injection jet, X-Plore, DSM, Netherlands). The mixing was carried out at processing temperature of $175^{\circ} \mathrm{C}$, screw speed of $50 \mathrm{rpm}$ and mixing time of $10 \mathrm{~min}$. The specimens were moulded at 8 bar injection pressure, $8 \mathrm{~s}$ injection time, hold on pressure bar, hold on time $4 \mathrm{~s}$ and mould temperature of $30^{\circ} \mathrm{C}$. The mould was then directly opened, the specimens were removed and then it allowed to cool down to room temperature. The PP/MA-g-PP/SF composites were prepared with the ratio $65: 5: 30$ with the optimized fibre length on the basis of optimum mechanical performance of the composites. To study the change in FO in 
the composites, all the above parameters were kept constant, only the mould temperature is varied and the composites were fabricated at 25,45 and $65^{\circ} \mathrm{C}$ mould temperatures.

\section{Theory}

\subsection{Mathematics of FO by image analysis}

Calculation of 3D FO during processing can be performed based on the assumption that the fibres are rigid cylinders of mono-disperse distribution in length and diameter and their concentration is spatially uniform throughout the composite. These assumptions are used to describe the orientation of population of fibres and also to develop the evolution equation [21]. It was necessary to make approximations and simplifying assumptions to facilitate image analysis so that fibre orientation can be determined easily from the end coordinates. Using these assumptions, the orientation of an individual fibre can be described by directional unit vector $\mathbf{p}$ aligned along the fibre axis. Cylindrical short fibre penetrate into the cut surface, oriented at a particular angle with respect to the cutting plane appears as an ellipse on the $2 \mathrm{D}$ section. These ellipses are used to construct the orientation of the fibres, its spatial orientation can be described using spherical coordinates with azimuthal angle $(\varnothing)$ and zenith angles $(\theta)$ illustrated in figure 2 [22]. The directions 1,2 and 3 refer respectively to the flow, width and thickness directions. The geometrical parameters measured from the ellipse were subsequently used to construct the vector of orientation as

$\mathbf{p}=\mathbf{p}_{1} \delta_{1}+\mathbf{p}_{2} \delta_{2}+\mathbf{p}_{3} \delta_{3} \quad(\delta$ is Kronecker delta function $)$.

The Cartesian components of $\mathbf{p}$ can be represented according to the following equations and are valid only for single fibre [24].

$$
\mathbf{p}_{1}=\sin \theta \cos \varnothing, \mathbf{p}_{2}=\sin \theta \sin \emptyset, \mathbf{p}_{3}=\cos \theta,
$$

where $\theta$ is the out of plane orientation angle and defined as the angle which is formed by the fibre with the sectioned surface normal. And $\varnothing$ is the in-plane orientation angle and defined as the angle which is formed by the major axis of the elliptical footprint with the vertical in-plane axis. Since both the end of fibres are not distinguishable and one description can be satisfied for the other, then [21-23]

$$
\mathbf{p}=-\mathbf{p}, \theta \rightarrow \pi-\theta, \varnothing \rightarrow \varnothing+\pi .
$$

The orientation of the major axis is identical to the angle $\varnothing$. The out-of-plane orientation angle $\theta$ is determined as the inverse cosine of the ratio of the semi-minor axis of the ellipse $(b)$ to the semi-major axis $(a)$. The associated angular relation can be represented as in the following way [22],

$$
\theta=\cos ^{-1} b / a \text {. }
$$

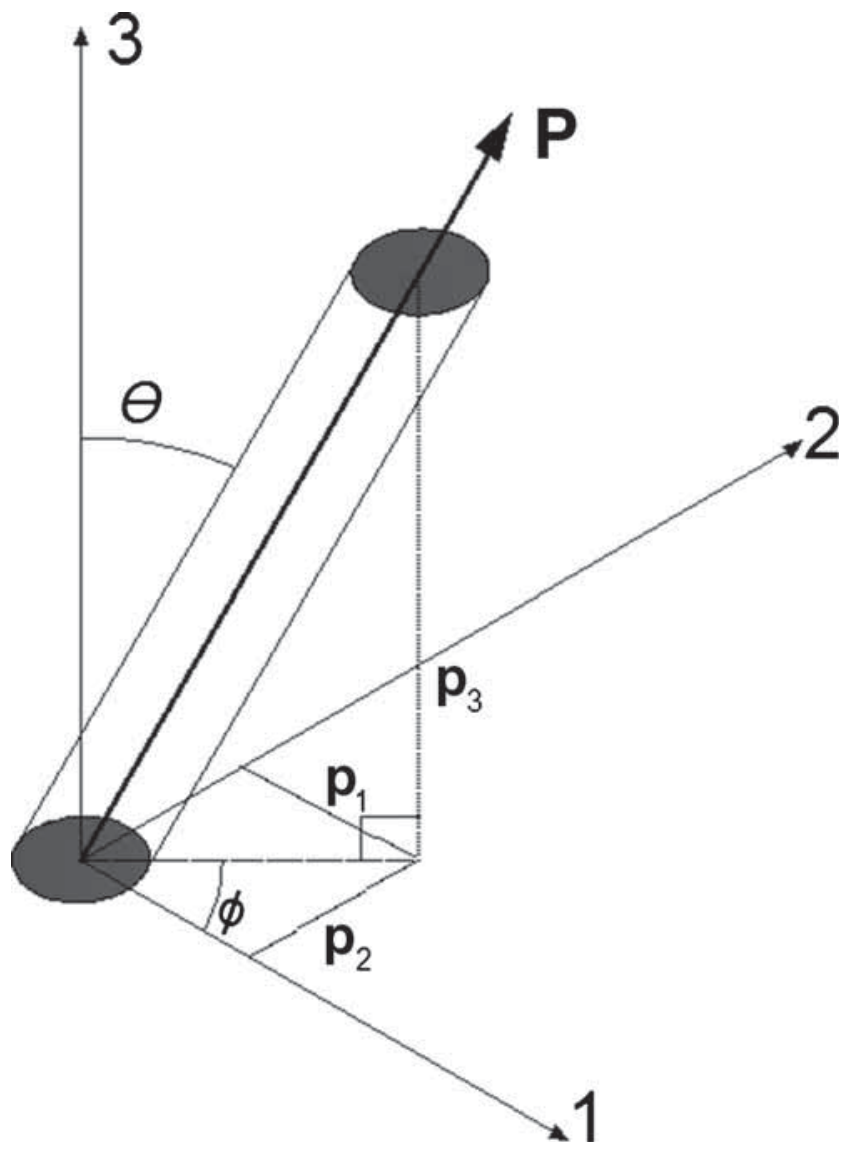

Figure 2. The orientation of a single fibre can be expressed in polar coordinates by two angles $(\theta, \varnothing)$ or in Cartesian coordinates by the components of a vector $\mathbf{P}\left(\mathbf{p}_{1}, \mathbf{p}_{2}, \mathbf{p}_{3}\right)$.

\subsection{FO tensor}

The tensorial notation is very much important to describe the FO of short fibre-reinforced injection moulded thermoplastic, because this description contains very less number of scalar quantities for the fibre orientation distribution (FOD) [19]. The tensor provides all the necessary information to model the behaviour of short fibre-reinforced composites with less computational efforts. It provides sufficient information needed to determine many anisotropic properties of the composites and its compactness is an additional strong point in favour of their use. The orientation tensors capture the stochastic nature of the fibre orientation distribution in a compact form. The FO tensor result shows the probability of fibre alignment in the specified principal direction [20].

The orientation tensor is related to the coefficients of a Fourier series expansion of the probability distribution function, because the distribution function is even; the odd order tensors are zero, so only even order tensors are taken into interest. If an $n$th order tensor property of a composite can be found from a linear average of a transversely isotropic tensor over the distribution function, then it is required to know the $n$th order orientation distribution function to predict the properties of composites [18]. 
The second-order orientation tensor has nine components similar to a $3 \times 3$ matrix but only five of these are independent because of the following two conditions.

$$
\left.\begin{array}{ll}
\text { Tensor symmetry } & \mathbf{a}_{i j}=\mathbf{a}_{j i}, \\
\text { Normalization condition } & \mathbf{a}_{11}+\mathbf{a}_{22}+\mathbf{a}_{33}=1 .
\end{array}\right\}
$$

Due to the normalization condition, the sum of diagonal elements is equal to unity; only two diagonal elements need to be determined. From the tensor symmetry, only three out-of-plane elements are required to be calculated [23].

The diagonal components of the second-order orientation tensor represent the strength of the alignment in the respective direction and their values range between 0 and 1 . The off-diagonal components indicate the deviation of the principle axes of the orientation from the geometric axes and they are zero when geometric axes coincide with the principal directions of the orientation tensor [7].

The second-order tensor can be calculated from the average orientation data obtained for the sample consisting on a group of $n$ fibres and the orientation angle of fibre can be transformed into component of second-order tensor component. It can be expressed by taking dyadic product of two directional unit vector $\mathbf{p}$ aligned in the principal fibre axis direction, and the number subscripts indicate the rank of FO tensor. The components of second-order tensor for a group of $n$ fibres are calculated as follows [25,26].

$$
\begin{aligned}
a_{i j} & =\frac{1}{n} \sum_{k=1}^{n} a_{i j}^{k}, \\
& =\frac{1}{n}\left(\sum_{k=1}^{n} p_{i}^{k} p_{j}^{k}\right)=\left(\begin{array}{lll}
a_{11} & a_{12} & a_{13} \\
a_{21} & a_{22} & a_{23} \\
a_{31} & a_{32} & a_{33}
\end{array}\right) .
\end{aligned}
$$

The six components for an individual fibre (based on symmetry condition) are as follows and $i, j=1,2,3$

$$
\left\{\begin{array}{l}
a_{11}=\sin ^{2} \theta \cdot \cos ^{2} \emptyset \\
a_{22}=\cos ^{2} \theta \cdot \cos ^{2} \emptyset \\
a_{33}=\cos ^{2} \theta \\
a_{12}=a_{21}=\sin 2 \cdot \cos ^{2} \emptyset \cdot \sin \emptyset \\
a_{13}=a_{31}=\sin \theta \cos \theta \cos \emptyset \\
a_{23}=a_{32}=\sin \theta \cos \theta \sin \emptyset
\end{array}\right.
$$

The three diagonal tensor components have been used in the consideration of FO state. $a_{11}$, FO in flow direction, varying from 0 to $1.0, a_{22}$, FO transverse to flow, varying from 0 to 1.0 and $a_{33}$, tilt of FO in the $1-3$ plane, varying from -0.5 to 0.5 . The flow direction orientation term $a_{11}$ contains most of the quantitative information about the microstructure and is most sensitive to flow, processing and material changes, so in this paper, only first diagonal component of the second-order orientation tensor is calculated [27].

$a_{11}<0.35$ indicates 3D FO, perpendicular to flow direction; $0.5<a_{11}<0.6$ indicates planar random FO; $a_{11}>0.7$ indicates unidirectional FO, parallel to flow direction. Orientation tensor with their physical interpretation as depicted
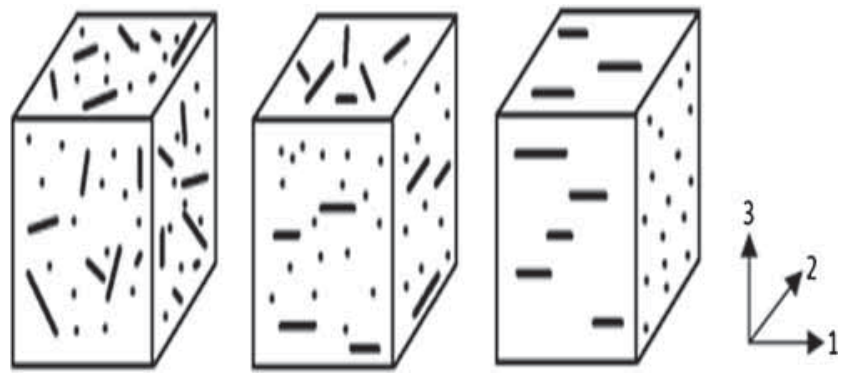

Figure 3. (a) 3D fibre orientation (3D random) perpendicular to flow direction, (b) 2D isotropic (planar random) orientation and (c) unidirectional fibre orientation (perfectly aligned) parallel to flow direction.

in figure 3a-d. Figure $3 a$ represents the fibres that are evenly distributed and oriented along three principal directions or the state of a 3D random orientation distribution, figure $3 \mathrm{~b}$ represents a biaxial arrangement in which fibres are evenly distributed and oriented along two principal directions, figure $3 \mathrm{c}$ represents a plane uniaxial arrangement in which fibres are aligned along a single direction [28-30].

$a_{i j}=\left(\begin{array}{ccc}\frac{1}{3} & 0 & 0 \\ 0 & \frac{1}{3} & 0 \\ 0 & 0 & \frac{1}{3}\end{array}\right), \quad a_{i j}=\left(\begin{array}{ccc}\frac{1}{2} & 0 & 0 \\ 0 & \frac{1}{2} & 0 \\ 0 & 0 & 0\end{array}\right), \quad a_{i j}=\left(\begin{array}{ccc}1 & 0 & 0 \\ 0 & 0 & 0 \\ 0 & 0 & 0\end{array}\right)$.
(a) $3 \mathrm{D}$ random
(b) Planar random
(c) Aligned

\subsection{Micromechanical model}

3.3a Modified rule of mixtures or area fraction method: Modified rule of mixtures (MRoM) is an analytical method which has been mostly used to predict the modulus and ultimate tensile strength of short fibre-reinforced composite. The theoretical prediction using MoRM can be made with the hypothesis of a perfect fibre-matrix interfacial bonding and based on the effects of fibre length, orientation distribution, the FO efficiency factor $\left(f_{\mathrm{o}}\right)$ or Krenchel orientation factor and fibre length efficiency factor $\left(f_{1}\right)$ or Cox shear lag factor [24]. This model proposed that the tensile strength of short fibre-reinforced thermoplastic composite is the sum of contributions from subcritical and supercritical fibres and also from the matrix [31].

3.3b Tensile strength: The formula of tensile strength is given by

$$
\sigma_{\mathrm{c}}=f_{\mathrm{o}} f_{\mathrm{l}} \sigma_{\mathrm{f}} V_{\mathrm{f}}+\sigma_{\mathrm{m}} V_{\mathrm{m}},
$$

where $\sigma_{\mathrm{c}}, \sigma_{\mathrm{f}}$ are the ultimate tensile strength of the composite and fibre, respectively; $V_{\mathrm{f}}, V_{\mathrm{m}}$ denote the volume fraction of the fibre and matrix; $\sigma_{\mathrm{m}}$ the stress developed in the matrix; $f_{\mathrm{o}}, f_{1}$ are the $\mathrm{FO}$ and fibre length efficiency factor, respectively. 
3.3c Tensile modulus: The tensile modulus can be calculated using the following equation:

$$
E_{\mathrm{c}}=f_{\mathrm{o}} f_{\mathrm{l}} E_{\mathrm{f}} V_{\mathrm{f}}+E_{\mathrm{m}} V_{\mathrm{m}},
$$

where $E_{\mathrm{c}}, E_{\mathrm{f}}, E_{\mathrm{M}}$ are tensile modulus of composite, fibre and matrix, respectively.

The FO factor $f_{\mathrm{o}}$ is the average value of the fourth-order orientation tensor with respect to the testing direction, and can be written as in the following [32],

$$
f_{\mathrm{o}}=\left(\cos ^{4} \emptyset\right) \text {. }
$$

\section{Results and discussion}

\subsection{Mechanical properties}

4.1a Mechanical strength of PP/SF composites at different fibre length: Polypropylene reinforced with $30 \mathrm{wt} \%$ of SF with fibre length of 3,6 and $10 \mathrm{~mm}$ were evaluated and the results including standard deviations (SD) are tabulated in table 1 . The tensile strength of composites at fibre length 3 , 6 and $10 \mathrm{~mm}$ were $33.26,38.51$ and 34.72 , respectively. The results of tensile behaviour of the composite at different fibre lengths showed that there exists an optimum fibre length at which maximum tensile properties were achieved. The optimum fibre length was $6 \mathrm{~mm}$ which reveals an increase in the tensile strength by $15.78 \%$ with increase in fibre length from 3 to $6 \mathrm{~mm}$, but further decreased by $9.84 \%$ at $10 \mathrm{~mm}$. The tensile moduli for the composites at different fibre lengths were 2269, 2341 and $2333 \mathrm{MPa}$, respectively. Tensile modulus showed a similar trend as that of tensile strength with respect to the fibre length.

The efficiency of a fibre-reinforced composites depend considerably on the adhesion between the fibre and matrix and the ability to transfer stress from the matrix to fibre. This result strongly reveals that the fibre length has profound effect on the composite properties [33]. The tensile strength and modulus showed maximum value at fibre length of $6 \mathrm{~mm}$ which was due to optimum load transmission from fibre to matrix at this fibre length as well as the adequate homogeneous distribution of fibres within the matrix.

The low tensile strength of the composite at fibre length of $3 \mathrm{~mm}$ has been obtained due to the short fibre length which is not sufficient enough for homogeneous distribution of load through fibre to matrix. Failure occurred easily when the fibre length was not suitable for homogeneous distribution of load. On the other hand, the decreasing behaviour of tensile strength and modulus might be due to the difficulty of adequately distributing and homogenizing of the fibre over the surface of matrix and incompatibility of fibre with matrix. For longer fibres (10 $\mathrm{mm}$ in this study), tensile strength has been decreased compared to $6 \mathrm{~mm}$ fibre length-reinforced composite material because longer fibre may not be compatible with the matrix which results weaker bonding between fibre and matrix. Further, folding of fibres might be occurring which results no bonding between the folded and unfolded portion of the fibre which prevented the proper alignment of the fibre in the composite [34]. Further, the reduction in tensile strength of the composite might be due the possibility of increasing fibre-rich and/or matrix-rich areas within the composite and also due to increased fibre entanglement with length which leads to improper fibre wetting in the matrix [35]. The increase in modulus at $6 \mathrm{~mm}$ and then decreased at $10 \mathrm{~mm}$ can also be attributed to the strong stress fields developed at the ends of the fibres in the composite beyond the $6 \mathrm{~mm}$ fibre length, which made the composite samples less tough [36].

The tensile strain of the composites at fibre length 3, 6 and $10 \mathrm{~mm}$ were found to be $4.86,5.19$ and $4.78 \%$. The impact strength of the composites were found to be $53.19,45.15$ and $44.15 \mathrm{~J} \mathrm{~m}^{-1}$ for the fibre length of 3,6 and $10 \mathrm{~mm}$, respectively, had opined that the impact strength of the composites can only be improved by decreasing the fibre length and by increasing the friction stress between the fibre and the matrix.

Hence, a proper length of the fibre is required for transmission of applied load and a good interfacial adhesion between the matrix and fibre, which is essential to improve the mechanical strength of composites. As at $6 \mathrm{~mm}$ fibre length, the composite results in maximum tensile strength and modulus, PP/SF composites at this length had been taken for further characterization study.

4.1b Mechanical properties of PP/SF/MA-g-PP composites of $6 \mathrm{~mm}$ fibre length at different mould temperatures: The composites with $30 \mathrm{wt} \%$ of SF at fibre length of $6 \mathrm{~mm}$ showed optimum mechanical properties as described in the sub-section 4.1a and this length was considered for the further preparation of PP/SF/MA-g-PP composites. The mechanical properties of $\mathrm{PP} / \mathrm{SF} / \mathrm{MA}-\mathrm{g}-\mathrm{PP}$ composite at a

Table 1. Mechanical properties of PP/SF composites at different fibre lengths.

\begin{tabular}{lcccc}
\hline $\begin{array}{l}\text { Sample composition } \\
(70 / 30 \mathrm{wt} \%)\end{array}$ & $\begin{array}{c}\text { Tensile strength } \\
(\mathrm{MPa})\end{array}$ & $\begin{array}{c}\text { Tensile modules } \\
(\mathrm{MPa})\end{array}$ & $\begin{array}{c}\text { Tensile } \\
\text { strain }(\%)\end{array}$ & $\begin{array}{c}\text { Notched impact } \\
\left(\mathrm{J} \mathrm{m}^{-1}\right)\end{array}$ \\
\hline $\mathrm{PP} / 3 \mathrm{~mm}$ of SF & $33.26 \pm 0.14$ & $2269 \pm 17$ & $4.86 \pm 0.43$ & $53.19 \pm 1.86$ \\
$\mathrm{PP} / 6 \mathrm{~mm}$ of SF & $38.51 \pm 0.17$ & $2541 \pm 12$ & $5.19 \pm 0.18$ & $45.15 \pm 1.15$ \\
$\mathrm{PP} / 10 \mathrm{~mm}$ of SF & $34.72 \pm 0.24$ & $2333 \pm 16$ & $4.78 \pm 0.32$ & $44.15 \pm 128$ \\
\hline
\end{tabular}


Table 2. Mechanical properties of PP/SF/MA-g-PP at different mould temperatures.

\begin{tabular}{lcccc}
\hline $\begin{array}{l}\text { Mould } \\
\text { temperature }\left({ }^{\circ} \mathrm{C}\right)\end{array}$ & $\begin{array}{c}\text { Tensile strength } \\
(\mathrm{MPa})\end{array}$ & $\begin{array}{c}\text { Tensile modulus } \\
(\mathrm{MPa})\end{array}$ & $\begin{array}{c}\text { Elongation } \\
\text { at break }\end{array}$ & $\begin{array}{c}\text { Impact strength } \\
\left(\mathrm{J} \mathrm{m}^{-1}\right)\end{array}$ \\
\hline 25 & $40.62 \pm 1.29$ & $1942 \pm 14$ & $6.38 \pm 0.23$ & $51 \pm 1.45$ \\
45 & $56.15 \pm 0.68$ & $2706 \pm 16$ & $4.93 \pm 0.17$ & $54 \pm 1.06$ \\
65 & $48.41 \pm 1.17$ & $2209 \pm 18$ & $5.82 \pm 0.22$ & $45 \pm 1.78$ \\
\hline
\end{tabular}

composition of 65/30/5 wt $\%$ of PP, SF and MA-g-PP, respectively, at different mould temperatures were studied and the results are depicted in table 2.

PP/SF/MA-g-PP composites with $6 \mathrm{~mm}$ fibre length at 65 : $30: 5$ ratio have resulted a significant increase in mechanical properties as compared to the mechanical strength of PP/SF composites, which is primarily attributed to the enhanced interfacial adhesion between the non-polar PP and polar SF through the formation of a chemical bridge between hydroxyl group of SF and carboxylic group of MA-g-PP. Furthermore, flexible PP chains of MA-g-PP are efficiently diffused into the matrix leading to physical inter-chain entanglements, thereby contributing to the mechanical continuity of the composites [37].

The tensile strength of $40.62,56.15$ and $48.41 \mathrm{MPa}$ were observed with respect to the mould temperature of 25,45 and $65^{\circ} \mathrm{C}$, respectively. With increase in mould temperature from 25 to $45^{\circ} \mathrm{C}$, tensile strength was increased by $38.23 \%$ which subsequently decreased at temperature of $65^{\circ} \mathrm{C}$ by $13.78 \%$ as compared to $45^{\circ} \mathrm{C}$ temperature because of the crystallization effect of the specimens. This significant effect of mould temperature on mechanical properties of polymer composites is due to the increase in temperature that results a perfect molecular packing or enhancement of crystallinity and thereby increases the rigidity and tensile strength [38]. When mould temperature is increased, at the same time cooling time should be increased to have more crystalline structures. But in the present study, all the other parameters including cooling time were kept constant, while only mould temperature is varied. Therefore, there was not enough time for the material to cool inside the mould with an increase in temperature. As the specimen immediately keep in touch with room temperatures (faster cooling) resulting lower crystallinity and hence lower strength was observed at higher mould temperature.

The modules of the composites were obtained as 1942, 2706 and $2209 \mathrm{MPa}$ at different mould temperatures of 25, 45 and $65^{\circ} \mathrm{C}$, respectively. It has been observed that the tensile modulus of composite prepared at $45^{\circ} \mathrm{C}$ mould temperature showed an increment of $39.34 \%$ as compared to the tensile modulus of composite at $25^{\circ} \mathrm{C}$ mould temperature and a significant decrease in tensile modulus of $18.37 \%$ at $65^{\circ} \mathrm{C}$ was obtained as compared to modulus at $45^{\circ} \mathrm{C}$.

Similarly, the impact strength increased when mould temperature increased from 25 to $45^{\circ} \mathrm{C}$ temperature and then decreased with further increasing to $65^{\circ} \mathrm{C}$. The impact strength increased at $45^{\circ} \mathrm{C}$ temperature by $5.88 \%$ and decreased to the tune of $16.67 \%$ with increase in the mould temperature from 45 to $65^{\circ} \mathrm{C}$. The decrease in impact strength at $65^{\circ} \mathrm{C}$ might be due to the increase in fibre degradation at higher mould temperature [39]. However, the mechanical strength of the composite at higher mould temperature might be increased if proper cooling time is applied during processing, so that filling flow to freeze slowly and the fibres have more time to align in the flow direction which has not yet been studied in the present investigation.

\subsection{Measurement of FO by SEM micrograph analysis}

The impact fractured surface of PP/SF/MAPP (65/30/5) prepared with mould temperature of 25,45 and $65^{\circ} \mathrm{C}$, are perpendicularly cut off to the mould flow direction and the cut sections of the mouldings were investigated by scanning electron microscopy (SEM). The difference in the mechanical strength of PP/SF and PP/SF/MAPP composites reflects good matrix/fibre adhesion in case PP/SF/MAPP. This might be because of better adaption of fibre to the resin matrix by using MAPP thus, indicating good wetting and strong interface. These micrographs are used to determine orientation of fibre within the composites by means of the angle between fibre and matrix. The quantification of FO of a sample involves the method of ellipse (MoE), which is commonly used for short fibre-reinforced composite to characterize the FO state [21]. It is the most preferable to evaluate FO state in the composites because of its extreme simplicity, less computational parameters and reduced cost. Using some geometrical assumptions this method can provide 3D orientation, which is based on the application of 2D information. The cutting fibre is more likely when it is perpendicular to the cutting plane than parallel to it [22]. The micrographs for respective temperatures were shown in figure $4 \mathrm{a}-\mathrm{f}$. The images show almost no sign of fibre agglomeration and microvoids in the fractured surface of specimens, indicating the fibres are well-adhered to the PP matrix.

For $25^{\circ} \mathrm{C}$ mould temperature the ratio of semi-minor axis of the ellipse $(b)$ to the semi-major axis $(a)$ is,

$$
\frac{b}{a}=\frac{39.04}{135.6}=0.28
$$

and

$$
\left\{\begin{array}{l}
\theta=\cos ^{-1} 0.28=73.73 \\
\varnothing=231.5
\end{array} .\right.
$$



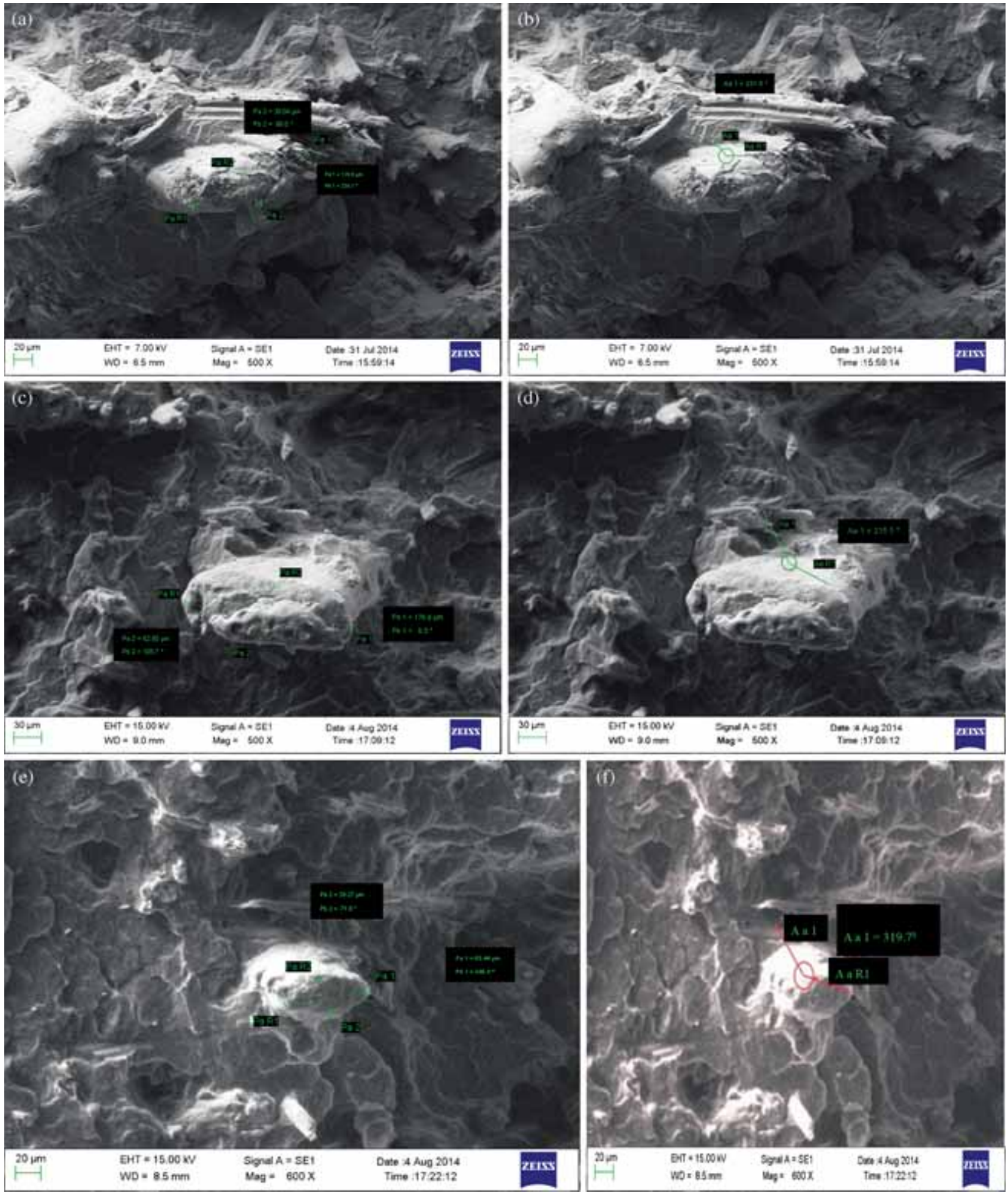

Figure 4. SEM micrographs for $(\mathbf{a}, \mathbf{b}) 25^{\circ} \mathrm{C},(\mathbf{c}, \mathbf{d}) 45^{\circ} \mathrm{C}$ and $(\mathbf{e}, \mathbf{f}) 65^{\circ} \mathrm{C}$ mould temperatures.

For $45^{\circ} \mathrm{C}$ mould tempereture, the ratio of semi-minor axis of the ellipse $(b)$ to the semi-major axis $(a)$ is,

$$
\begin{gathered}
\frac{b}{a}=\frac{62.50}{176.6}=0.35 \\
\text { and }\left\{\begin{array}{l}
\theta=\cos ^{-1} 0.35=69.51 \\
\varnothing=215.5
\end{array}\right.
\end{gathered}
$$

For $65^{\circ} \mathrm{C}$ mould temperature, the ratio of semi-minor axis of the ellipse $(b)$ to the semi-major axis $(a)$ is,

$$
\begin{gathered}
\frac{b}{a}=\frac{29.27}{63.44}=0.46, \\
\text { and }\left\{\begin{array}{l}
\theta=\cos ^{-1} 0.46=62.61 \\
\emptyset=319.7
\end{array}\right.
\end{gathered}
$$




\subsection{Calculation of orientation tensor}

For $25^{\circ} \mathrm{C}$ mould temperature

$$
\theta=73.73 \text { and } \varnothing=231.5 .
$$

From the model

$$
\begin{aligned}
a_{11} & =\sin ^{2} \theta \cdot \cos ^{2} \emptyset=\frac{1-\cos 2 \theta}{2} \frac{1+\cos 2 \emptyset}{2}, \\
& =\frac{1-\cos 147.46}{2} \frac{1+\cos 463}{2}, \\
& =\frac{1+0.84}{2} \frac{1-022}{2}, \\
& =0.92 \times 0.39, \\
& =0.35 .
\end{aligned}
$$

Thus, the alignment at $25^{\circ} \mathrm{C}$ mould temperature is $3 \mathrm{D}$ random (quasi isotropic) and slightly aligned, i.e., perpendicular to flow direction.

For $45^{\circ} \mathrm{C}$ mould temperature

$$
\theta=69.51 \text { and } \emptyset=215.5 \text {. }
$$

Similarly by using the above formula

$$
a_{11}=0.57 \text {. }
$$

So the alignment is planar random (2D isotropic) and moderately aligned.

For $65^{\circ} \mathrm{C}$ mould temperature

$$
\theta=62.61 \text { and } \varnothing=319.7 \text {. }
$$

Using the given formula

$$
a_{11}=0.45 \text {. }
$$

And the alignment at $65^{\circ} \mathrm{C}$ mould temperature is $3 \mathrm{D}$ random (quasi isotropic) and slightly aligned, i.e., perpendicular to flow direction.

\subsection{Determination of mechanical strength using MRoM}

For $25^{\circ} \mathrm{C}$ mould temperature

$$
\emptyset=231.5 \text {. }
$$

Then

$$
\begin{aligned}
f_{\mathrm{o}} & =\left(\cos ^{4} 231.5\right), \\
& =0.15 .
\end{aligned}
$$

For $45^{\circ} \mathrm{C}$ mould temperature

$$
\begin{aligned}
\emptyset & =215.5, \\
f_{\mathrm{o}} & =0.43 .
\end{aligned}
$$

For $65^{\circ} \mathrm{C}$ mould temperature

$$
\begin{aligned}
\varnothing & =319.7, \\
f_{0} & =0.33 .
\end{aligned}
$$

As it has assumed about the uniform length of fibre $(l)$, the critical fibre length concept was used to determine fibre length efficiency factor and can be obtained from the following formula [24],

$$
\left\{\begin{array}{l}
f_{1}=\frac{l}{2 l_{\mathrm{c}}} \text { for } l<l_{\mathrm{c}} \\
f_{1}=1-\frac{l_{\mathrm{c}}}{2 l} \text { for } l<l_{\mathrm{c}}
\end{array},\right.
$$

where $l_{\mathrm{c}}$ is the critical minimum fibre length in its simplest form, critical length is given by,

$$
l_{\mathrm{c}}=\frac{\sigma f d}{2 \tau},
$$

where $d$ is the fibre diameter and $\tau$ the interfacial shear strength between fibre and matrix. In case of strong interfacial bonding between the fibre and matrix, the load transfer into the fibre will be governed by shear-yielding action of the matrix, that means $\tau$ is limited by the shear strength of the matrix. Therefore, using the Von misses criteria, the maximum transferable shear is as follows [40],

$$
\tau=\frac{\sigma_{\mathrm{m}}}{\sqrt{3}} .
$$

As the ultimate tensile strength of PP is $29.13 \mathrm{MPa}$, then interfacial shear strength is determined as $16.81 \mathrm{MPa}$.

The tensile strength of SF is $479.322 \mathrm{MPa}$ and diameter is $0.168 \mathrm{~mm}$, then the critical fibre length can be calculated as

$$
\begin{aligned}
l_{\mathrm{c}} & =\frac{479.322 \times 0.168 \times 10^{6}}{2 \times 16.82 \times 10^{6}}, \\
& =\frac{80.526}{33.62}, \\
& =2.39 \mathrm{~mm} .
\end{aligned}
$$

As critical length is less than the optimized fibre length $(6 \mathrm{~mm})$ used for the preparation of the composite, thus the fibre length efficiency factor $f_{1}$ can be derived using the following formula:

$$
\begin{aligned}
f_{1} & =1-\frac{l_{\mathrm{c}}}{2 l} \quad\left(\text { as } l \geq l_{\mathrm{c}}\right), \\
& =1-\frac{2.39}{2 \times 6}, \\
& =0.81 \mathrm{~mm} .
\end{aligned}
$$

Theoretical calculations for strength, modulus and other properties of a fibre-reinforced composite are based on the fibre volume fraction of the material. From the experimental data, weight fraction of the matrix and fibre are 0.7 and $0.3 \%$, respectively and densities of fibre and matrix are 1.5 and $0.9 \mathrm{~g} \mathrm{cc}^{-1}$, respectively, then volume fraction of the fibre can be calculated using the following formula:

$$
\begin{aligned}
v_{\mathrm{f}} & =\frac{w_{\mathrm{f}} / \rho_{\mathrm{f}}}{w_{\mathrm{f}} / \rho_{\mathrm{f}}+w_{\mathrm{m}} / \rho_{\mathrm{m}}} \quad \text { and } \quad V_{\mathrm{m}}=\left(1-v_{\mathrm{f}}\right), \\
& =\frac{0.2}{0.2+0.7}=0.22 .
\end{aligned}
$$


Matrix volume fraction is, $V_{\mathrm{m}}=\left(1-v_{\mathrm{f}}\right)$,

$$
\begin{aligned}
& =(1-0.22), \\
& =(0.78)
\end{aligned}
$$

According to MRoM, for $25^{\circ} \mathrm{C}$ mould temperature, tensile strength can be calculated as follows,

$$
\begin{aligned}
\sigma_{\mathrm{cu}} & =0.15 \times 0.81 \times 0.22 \times 479.322+0.78 \times 29.13 \\
& =35.53 \mathrm{MPa} .
\end{aligned}
$$

And tensile modulus can be calculated as

$$
\begin{aligned}
E_{\mathrm{c}} & =0.15 \times 0.81 \times 0.22 \times 28503.418+0.78 \times 920.693 \\
& =1480.03 \mathrm{MPa} .
\end{aligned}
$$

For $45^{\circ} \mathrm{C}$ mould temperature, tensile strength can be written as

$$
\begin{aligned}
\sigma_{\mathrm{c}} & =0.43 \times 0.81 \times 0.22 \times 479.322+0.78 \times 29.13 \\
& =59.44 \mathrm{MPa} .
\end{aligned}
$$

And tensile modulus can be obtained as

$$
\begin{aligned}
E_{\mathrm{c}} & =0.43 \times 0.81 \times 0.22 \times 28503.418+0.78 \times 920.693 \\
& =2902.24 \mathrm{MPa} .
\end{aligned}
$$

For $65^{\circ} \mathrm{C}$ mould temperature, tensile strength can be written as

$$
\begin{aligned}
\sigma_{\mathrm{c}} & =0.33 \times 0.81 \times 0.22 \times 479.322+0.78 \times 29.13 \\
& =50.90 \mathrm{MPa} .
\end{aligned}
$$

And tensile modulus can be obtained as

$$
\begin{aligned}
E_{\mathrm{c}} & =0.33 \times 0.81 \times 0.22 \times 28503.418+0.78 \times 920.693 \\
& =2394.31 \mathrm{MPa} .
\end{aligned}
$$

A comparative account of experimental tensile strength of PP/MA-g-PP/SF composites prepared by different mould temperatures with the theoretical mathematical model was studied. Figure 5 demonstrates the comparison of the tensile strength of composites obtained from experimental data and theoretically predicted values as per MRoM model against mould temperatures 25,45 and $65^{\circ} \mathrm{C}$. The comparative study of experimental results with the theoretical prediction obtained from MRoM model have been observed. A significant deviation between the experimental and theoretically predicted tensile strength has been observed. It has been found that the theoretically predicted tensile strength at 25 , 45 and $65^{\circ} \mathrm{C}$ mould temperatures are $12.53 \%$ lower, $5.53 \%$ higher and $4.89 \%$ higher, respectively, as compared to the corresponding experimental tensile strength at that respective mould temperature.

Thus, it is indicated that the mechanical strength of the composites strongly depend on FO, fibre volume fraction, stress concentration at the fibre ends and critical fibre length. As in the present study, the length of the fibre was kept constant, the fibre length efficiency factor not became as much effective for the variation of the properties and hence the fibre

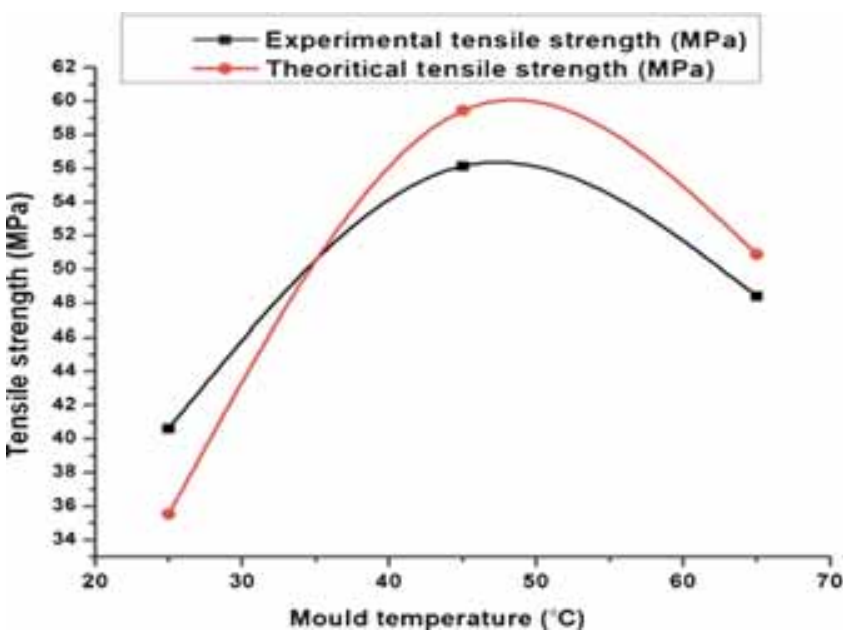

Figure 5. Experimental and theoretical tensile strengths at different mould temperatures.

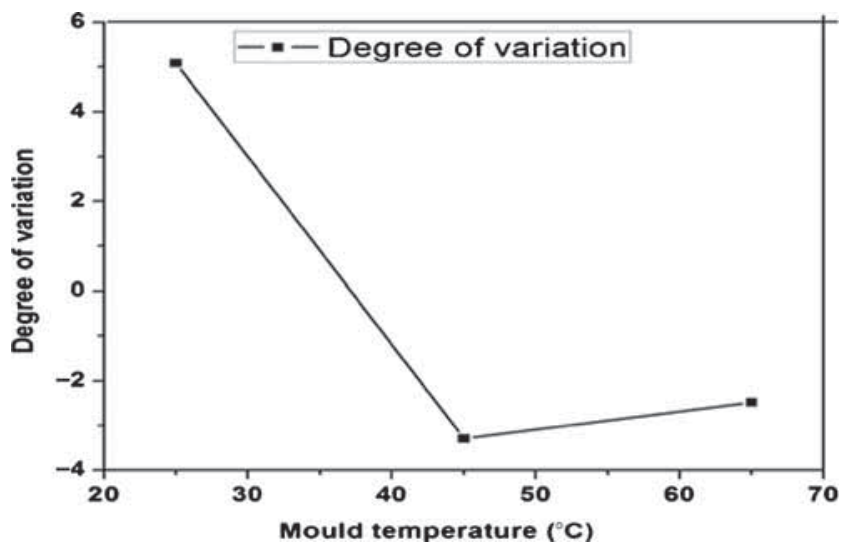

Figure 6. Degree of variation of tensile strength at different mould temperatures.

length did not contribute to the variation of tensile strength obtained experimentally and also with theoretically predicted value. Variation of the FO state in the composite might be the probable reason for mismatching of the theoretical strength obtained by the model with experimental data [31]. The predicted values by the MRoM model are inferior to the experimental values at mould temperature $25^{\circ} \mathrm{C}$ for lower FO. The significant deviation of theoretical and experimental results can be explained by the formation of micro-crack at the fibre-matrix interface due to large variation in tensile strength of individual SF, which in turn results in a decrease in experimental mechanical properties. Also another reason for this is constant cooling time at higher mould temperature results lower crystallinity and hence, lower tensile strength.

Figure 6 shows the deviation from the theoretical value predicted by the micromechanical model, which has been presented in $y$-axis as degree of difference plotted against experimental value obtained at different mould temperatures. The negative value indicates the lower experimental value 
than that of the predicted value and the positive value indicate higher experimental value from the model.

\section{Conclusion}

In the present study, the influence of injection moulding process parameter (here mould temperature was taken) to study difference in FO in composite with respect to temperature. The polar angles $(\theta, \varnothing)$ obtained from the SEM micrographs used by the second-order orientation tensor to determine the FO state in the composites prepared at different mould temperatures. The results of experimental FO characterization were presented in terms of $a_{11}$, the first component of secondorder orientation tensor. The tensile strength of the composites has been determined successfully both experimentally and theoretically by using micromechanical model (MRoM). The theoretical result obtained from the model was compared with the experimental data obtained, and it shows satisfying agreement. Results and conclusions obtained during this study can be summarized as:

(i) Composite prepared using $6 \mathrm{~mm}$ fibre length showed enhanced mechanical propertiesas compared with those of 3 and $10 \mathrm{~mm}$.

(ii) Experimental results indicated a remarkable change in the mechanical strength of the composite that was obtained as a function of mould temperature.

(iii) The in-plane orientation angle $\varnothing$ and out-planeorientation angle $\theta$ of different composites determined from SEM images.

(iv) The change in the value of $a_{11}$ (first orientation tensor component in the flow direction at different mould temperatures) was successfully determined and it was observed that FO in an injection-moulded composite has a significant influence on the mechanical strength of different areas of the injected part.

(v) A micromechanical model MRoM has been introduced to predict tensile strength and modulus taking into consideration the effect of FO. It has been observed that the experimental results are well in line with the theoretical predictions.

\section{References}

[1] Cheung H Y and Ho M P 2009 Compos: Part B 40655

[2] Joseph P V and Thomas Sabu 1999 Compos. Sci. Tech. 59 1625

[3] Shao-Yun Fu and Bernd Lauke 1997 J. Mates. Sci. 321985

[4] Ahmed N Oumer and Othman Mamat 2009 IJMME-IJENS 918

[5] Cansever C C 2007 Middle East Technical Uiversity

[6] Mathew L and Joseph R 2007 J. Appl. Polym. Sci. 1031640

[7] Mlekusch B 1999 Compos. Sci. Tech. 59547
[8] Coindreau O and Vignoles G 2003 Nucl. Instr. Meth. Phys. Res. B 200308

[9] Eberhardt C and Clarke A 2001 Compos. Sci. Tech. 61 1389

[10] Lee K S, Lee S W, Youn J R, Kang T J and Chung K 2001 Fibres Polym. 241

[11] Yang H and Colton J S 1994 Polym. Compos. 146

[12] Davidson N C, Clarke A R and Archenhold G 1997 J. Microsc. 185233

[13] Sterio D C 1984 J. Microsc. 134127

[14] Sirkis J S, Cheng A and Dasgupta A 1994 J. Compos. Mater. 28784

[15] Fischer G and Eyerer P 1988 Polym. Compos. 9297

[16] Zhu Y T and Lowe T C 1998 J. Compos. Mater. 58389

[17] Gonzales L M and Cumbera F L 1994 Acta Metal. Mater. 42 689

[18] Advani S G and Tucker C L 1987 J. Rheol. 31751

[19] Bay R S and Tucker C L III 1992 Polym. Eng. Sci. 32240

[20] Neves N M, Isdell G and Pouzada A S 1998 Polym. Compos. 19640

[21] Hofmann T, Baird Donald and M Gregario 2013 Polym. Comp. 34390

[22] Michel Vincenta, Girouda T and Eberhardt C 2005 Polymer 466719

[23] Lee Y H and Youn J R 2002 Mat. Res. Innovat. 665

[24] Patcharaphun and Somjate 2006 Institute of Mechanical and Plastics Engineering, Chemnitz University of Technology

[25] Colin E B and Clarke A 2001 Compos. Sci. Tech. 611961

[26] Josef B L and Microslav K O 2014 Slovak University of Technology 22109

[27] Jacek N B 2011 Kompozyty Comp. 11347

[28] Du H C and Tai H K 2002 J. Rheol. 14175

[29] Xiongqi Peng and Yugang Jilang 2015 Brit. J. Appl. Sci. Technol. 7186

[30] Tucker C L and Advani S G 1994 Comp. Mater. Seri. Amsterdam 147123

[31] Jandas P, Mohanty S and Nayak S K 2013 J. Appl. Polym. Sci. 1274027

[32] Hine P, Parveen B and Brands D 2014 Composites Part A 64 70

[33] Mylsamy and Rajendran M 2011 Mater. Des. 324629

[34] Islam M A and Rizvi F B 2006 J. Novel Arch. Marine Engg. 31

[35] Sumila M and Amber L 2013 Asian J. Natural Appl. Sci. 2 139

[36] Abdelmouleh and Boufi M 2007 Compos. Sci. Tech. 671627

[37] Kabir M M and Wang H 2012 Composites Part B 432883

[38] Sada Abadi H and Ghasemi M 2007 J. Reinfor. Plast. Compos. 261729

[39] Cahit C Cansever Ph.D thesis, Graduate School of Natural and Applied Sciences, Middle East Technical University (submitted)

[40] Carlsson J 2012 Master thesis, Department of Applied Mechanics, Chalmers University of Technology (submitted) 